\title{
Pandemia, confinamiento y educación a distancia: una valoración universitaria en la Ciudad de México
}

\author{
ANNA MARÍA FERNÁNDEZ PONCELA* \\ Universidad Autónoma Metropolitana - México \\ Recibido el 14-10-20; evaluado el 04-07-21; \\ aceptado el 29-07-21
}

\section{Resumen}

Este texto es un acercamiento a la valoración estudiantil de la situación de pandemia, confinamiento, y de manera particular la educación a distancia. El objetivo es conocer las actitudes de las y los jóvenes universitarios en torno a las nuevas formas de enseñanza aprendizaje, sin perder de vista su estado de ánimo, pensar y sentir sobre el contexto sanitario y social. Para conseguir este objetivo se cuenta con descripciones solicitadas por escrito a treinta estudiantes, sobre su valoración de la situación del entorno, lo que pensaban y lo que sentían. Respecto a la educación a distancia los estudiantes declaran satisfacción por seguir estudiando y frustración por el distanciamiento social. Se ponen también de manifiesto dificultades del uso masivo e intensivo de la tecnología digital, y la insistencia de regresar a la escuela.

Palabras clave: actitudes, educación a distancia, pandemia, estudiantes, México.

\section{Pandemic, confinement, and distance education: a university assessment in Mexico City}

\section{Abstract}

This text is an approach to the student's assessment of the situation the pandemic, confinement, and in particular way distance education. The objective is to know the attitudes of young university students regarding new forms of teachinglearning, without losing sight of their state of mind, thinking and feeling about the health and social context. To achieve this objective, there are written descriptions requested from thirty students about their assessment of the surrounding

\footnotetext{
* Doctora en Antropología, estudios en Psicología y Sociología. Investigadora y docente de la Universidad Autónoma Metropolitana (México), en carreras de Ciencias Sociales y el doctorado. Miembro de la Academia Mexicana de Ciencias y del Sistema Nacional de Investigadores. Autora de artículos y libros, algunos en torno al espacio educativo como Humor en el aula (2016). https://orcid.org/0000-0003-3080-212X. Correo electrónico: fpam1721@correo.xoc.uam.mx
} 
situation, what they thought and what they felt. Regarding distance education, students declare satisfaction for continuing to study and frustration for social distancing. Difficulties of the massive and intensive use of digital technology, and the insistence to return to school are also revealed.

Keywords: attitudes, distance education, pandemic, university students, México.

\section{Pandemia, confinamento e educaçáo a distância: uma avaliaçáo universitária na Cidade do México}

\section{Resumo}

Este texto é uma abordagem à avaliação do aluno sobre a situação a pandemia, o confinamento e, de uma forma particular, a educação a distância. O objetivo é conhecer as atitudes de jovens universitários frente às novas formas de ensino-aprendizagem, sem perder de vista seu estado de espírito, pensando e sentindo sobre a saúde e o contexto social. Para isso, há descriçôes solicitadas por escrito, para a avaliaçáo da situação do ambiente com atitudes. Em relação à educação a distância, declaram-se a satisfação em continuar estudando e a frustração com o dis tanciamento social, bem como as dificuldades do uso massivo e intensivo da tecnologia digital, aliadas à insistência em retornar às aulas. Em suma, existem posiçôes reativas e pró-ativas, sendo as últimas geralmente importantes em termos de educação digital.

Palavras-chave: atitudes, educação a distância, pandemia, estudantes, México.

\section{INTRODUCCIÓN}

El año 2020 cambió la vida de millones de habitantes en la tierra, en febrero la Organización Mundial de la Salud (OMS) declaró la pandemia de la COVID19, una enfermedad que al parecer había aparecido en China a finales del año anterior (2020). La sanidad de los países se vio trastocada y en el futuro ya no será la misma, no solo porque se dejó al descubierto su importancia y porque se hizo notorio su descuido en los últimos años, sino porque poco a poco se van a ir abriendo paso algunos nuevos conocimientos, más allá de la farmacopea clásica y las vacunas, entre otras cosas. Por no citar otras transformaciones mentales y emocionales, no solo las evidentes como la pandemia de miedo existente, sino y también la introspección que de una u otra manera tal situación ha obligado a todo mundo realizar. Algunas de estas afirmaciones se verán más adelante según la mirada y la voz de un grupo de estudiantes, pero lo que sobre todo interesa son los cambios en la educación y su percepción desde las actitudes de jóvenes universitarios que de un día para otro transitaron de las 
clases presenciales a las clases remotas, ante la emergencia sanitaria y las decisiones que las autoridades gubernamentales tomaron al respecto, y la respuesta de las instituciones de educación que tuvieron que decidir también de forma urgente y emergente pasarse al sistema de educación por medio de las tecnologías de la información y la comunicación, que aunque conocidas no por ello desarrolladas como forma usual de enseñanza aprendizaje, por lo menos hasta ahora.

Todo lo cual como de alguna manera se ha dicho, implica un cambio largo y profundo en cuanto a la organización del mundo y la vida que traerá consigo un auge de la robotización, digitalización, automatización, la inteligencia artificial y el trabajo on line, además de y por supuesto, la educación virtual que ya iniciaba su recorrido, pero que ahora ha sido empujada de forma urgente a sentar las bases de la ampliación y masificación de la misma, su perpetuación hacia el futuro no sabemos si en combinación con la presencial o quizás incluso de manera exclusiva en algún momento de la historia. Varios autores en el mundo discuten sobre el camino que reconducirá los cambios políticos y económicos en distintas direcciones (Dussel, 2020; Zibechi, 2020; Han, 2020; Zizek, 2020). Lo que sí parece más que claro es que la tecnologización y virtualización de la cotidianidad llegaron para quedarse (Han, 2014; Lasalle, 2019). Lo cual implica un cambio paradigmático de largo alcance que incluye a la ciencia (Kuhn, 1986), y por supuesto a la educación, más allá de lo digital (Organización de las Naciones Unidas para la Educación, la Ciencia y la Cultura - Unesco, 2014).

En el caso de la Universidad Autónoma Metropolitana (UAM), centro de educación superior de carácter público en la ciudad de México, y ante la suspensión de clases por la pandemia y la declaración de emergencia del gobierno, se diseñó y desarrollo el Proyecto Emergente de Educación Remota que intenta recoger y exponer soluciones creativas e innovadoras con objeto de proseguir con las funciones sustantivas de docencia según las posibilidades tecnológicas de profesorado y alumnado. Lo cual posibilitó realizar el trimestre en línea — según la educación a distancia, virtual u online propiamente- que dicha institución educativa denominó remota (UAM, 2020). Todo ello en el marco de la Organización de las Naciones Unidas (ONU) (2020) con objeto de seguir con las políticas educativas presentes y futuras.

Aquí se presenta un ejercicio cualitativo realizado a universitarios de la UAM, plantel Xochimilco, Ciudad de México, que alumbrará en torno a las actitudes ante lo que aconteció en los primeros meses de 2020 sobre la pandemia y el quedarse en casa, así como, con relación a la educación remota que desarrollaron en esos momentos, reiteramos de forma sorpresiva y urgente. 
En concreto, recordamos y reiteramos el objetivo esbozado, la valoración general y particularmente las actitudes concretas de jóvenes estudiantes universitarios de un centro público de la Ciudad de México ante la implantación de la enseńanza remota, así como, su estado anímico y su posicionamiento frente a la noticia de la pandemia, primero en China y con posterioridad su llegada a México, y la medida de confinamiento tomada por las autoridades sanitarias del país. En el siguiente punto se ahonda sobre conceptos y método.

\section{MARCo TEÓRICO}

Iniciamos con una definición básica y clásica de las actitudes según la de Allport (1935) que las considera como disposición mental que se adapta a las circunstancias, relacionada con la herencia y con la socialización y la personalidad, que predispone a reacciones de la persona y crea tendencia o disposición a pensar y sentir, así como actuar de determinada manera y perdura en el tiempo. Hoy es posible afirmar que se trata de evaluaciones generales y estables que alguien realiza sobre algo o alguien (Briñol et al., 2007). Hay diferentes concepciones que presentan ciertas variaciones, no obstante, y en lo fundamental, las actitudes tienen que ver con cogniciones - evaluaciones, valores, creencias - que es la forma de pensar; con emociones y sentimientos o la forma de sentir; y la conducta o la manera de reaccionar, hacer y actuar Ubillos et al., 2014). Por supuesto, influyen en la percepción y gozan de estabilidad y duración, lo que las hace consistentes y perdurables (Ubillos, et al., 2014). No por ello, dejan de ser a veces ambivalentes, y por supuesto cambiantes pese a su tendencia a la reproducción, obvian las contradicciones y prefieren mantenerse (Briñol et al., 2007).

Añadir que sus funciones son de conocimiento — procesar información, ordenar el mundo y dotarlo de significado-; instrumental — conseguir y librar cosas-; defensiva - evitar conflictos, enfrentar emociones como la ansiedad, garantizar seguridad—; valorativas — evaluar desde la satisfacción de necesidades psicológicas, desde fortalecer el autoconcepto y la identidad, hasta mantener ideales y sistemas normativos-; adaptativas -integración grupal y adaptación social— (Briñol et al., 2007; Ubillos et al., 2014).

Su tipología es diversa, no obstante, en una primera clasificación destaca la valoración de las circunstancias y el ambiente — positiva y optimista, sana, confiada, estimula la acción—, negativa y pesimista — se centra en lo adverso, las dificultades, quejas y evita la acción-y también está la neutra. Otro tipo es según la orientación a la actividad: proactiva —activa y persigue mejorar, solucionar problemas, crear alternativas-, reactiva — pasiva, dependiente, 
conformista con lo establecido y proclive a la inacción-. Luego está la actitud que motiva a actuar, y que puede ser de forma interesada - persiguiendo intereses y beneficios particulares y propios - o desinteresada y altruista - que busca el beneficio colectivo y promueve la empatía-. Con relación a las otras personas hay también una amplia clasificación de actitudes —algunas relacionadas de forma directa o indirecta con las anteriores-, tales como, la colaborativa e integradora, manipuladora, pasiva, sumisa, agresiva, asertiva, pesimista, flexible, inflexible, nihilista y moralista o prejuiciosa (Bohner y Dikel, 2010; Ajzen, 2005).

La forma de trabajar las actitudes se realiza a través de revisar los relatos recabados entre el estudiantado y ordenarlas según campos sociosemánticos, esto es, agrupación de tendencias respecto a su concepción y tipología, conceptos y contexto, semántica e ideología, revisando lo expuesto como un texto social y considerando el significado de palabras y grupos de palabras y su semejanza al compartir características comunes de significado con parentesco semántico y extrasemántico (Corrales, 1991). Todo ello, en un contexto de estructura comunicativa y social determinado, además del significado, el contenido y las ideologías existentes. Lo cual deviene y se plasma en una matriz de codificación de conceptos de similaridad socio semántica (Díaz, 2000). En este caso, circunscrito a lo actitudinal, que forma parte de representaciones sociales e imaginarios colectivos, entre otras cosas, como la relación con la ideología y las estructuras de esquemas mentales (Rodríguez, 2004).

Finalizar este apartado teórico conceptual con el señalamiento de la importancia de las emociones, sentimientos y estados de ánimos, como componente actitudinal, y también como en concreto las emociones denominadas positivas tienen un peso importante adaptativo a la vida y la mirada propositiva de la misma, incluida la educación, por supuesto, como se verá a lo largo de este texto (Fredrickson, 2004; Seligman, 2014).

\section{Metodología}

Se trata, como se ha dicho, de una aproximación inicial a la valoración del entorno y la situación que causó el coronavirus y las medidas de sana distancia y quedarse en casa, así como, de valoración de la educación a distancia, que por las circunstancias tuvo que iniciarse y desarrollarse con carácter emergente en México y en varios países del planeta. Es un trabajo empírico, exploratorio, cualitativo (Valles, 1997), que se centra en la información recabada en relatos realizados en redactados y su análisis se focaliza en actitudes, y para revisar los datos cualitativos se desarrolló todo el proceso de segmentación, codificación, 
categorización y análisis correspondiente (Cohen y Seid, 2019), esto teniendo en cuenta las actitudes declaradas y los campos semánticos (Corrales, 1991). Es un estudio por lo tanto de carácter inicial y descriptivo, en torno a ocho interrogantes dobles que al no poder ser aplicados en una entrevista (Lupton, 2020), se optó por ser solicitados a modo de descripción por escrito a través de redactados inspirados en el interrogante solicitado. Reúne pensamientos y sentimientos sobre cuatro temas, con doble pregunta sobre los mismos, en total ocho, como se dijo. Con objeto de clarificar y aligerar la exposición de los datos e información se optó por realizar y presentar a modo de cuadros o tablas semánticas, parte del proceso de análisis llevado a cabo (Cohen y Seid, 2019), guiados por la clasificación de actitudes y con objeto de mostrar la valoración realizada por un grupo de estudiantes, en total treinta, todo ello ante los cambios metodológicos que obliga la pandemia (Lupton, 2020).

En concreto, se trató de una treintena de jóvenes universitarios de la UAM (Xochimilco) en la ciudad de México, mitad hombres y mitad mujeres, de entre 18 y 20 años, estudiantes de las diversas carreras que se imparten en dicha institución de educación superior, siendo una muestra intencional y oportunista. El instrumento se aplicó en el mes de junio de 2020 (en medio del trimestre lectivo que tenía lugar por internet), y constó como se dijo, en la realización de un redactado descriptivo solicitado a modo de respuesta a cuatro interrogantes concretos sobre ciertas circunstancias, cada uno de los cuales en su doble versión cognitiva y emocional de la actitud: lo que sienten y lo que piensan. Fueron ocho redactados por persona con un total de 240 narraciones obtenidas. El enfoque cualitativo es importante (Valles, 1997), pues se desea conocer opiniones y sentimientos, reflexiones y estados de ánimo, en fin, su mirada descriptiva, narrativa, explicativa sobre lo que acontece según su relato, y de manera particular sus emociones y pensamientos de la educación a distancia que por primera vez realizaron, en concreto sus vivencias y experiencias (Rogers, 2007). A continuación, se presenta el instrumento aplicado, la elección de las preguntas en concreto se debe a una línea de tiempo, desde la noticia internacional de un virus y una pandemia, hasta la noticia sobre su llegada al país. Esto es una comparación entre verlo lejos de espacio, temporalmente hablando, y considerarlo cerca o aquí y ahora, por una parte. Por otra parte, están las dos situaciones clave, consecuencia de la alerta sanitaria y las medidas tomadas por el gobierno, el confinamiento y en el caso del ámbito escolar, las clases a distancia, preocupaciones máximas en su momento. Con la finalidad de obtener información más concreta y específica de las actitudes, se solicitó el pensar y sentir, esto es, lo cognitivo y lo emocional que sobresalen en el enfoque actitudinal. 
I. Al oír por primera vez sobre el coronavirus en China:

¿Qué sentiste?

¿Qué pensaste?

II. Cuando se informó que el coronavirus llegó a México:

¿Qué sentiste?

¿Qué pensaste?

III. Sobre el confinamiento que está teniendo lugar:

¿Qué sientes?

¿Qué piensas?

IV. Sobre las clases a distancia:

¿Qué sientes?

¿Qué piensas?

Si bien es de gran interés el último punto, ya que se trata de algo novedoso en su versión masiva y obligatoria en el espacio educativo del país, y que es preciso aprehender en la medida de lo posible con objeto de mejorar, dado que al parecer se seguirá por un tiempo en esa modalidad instructiva, no hay que desestimar la información sobre el contexto en el cual estas personas se desenvuelven, además de su posicionamiento y estado de ánimo sobre las clases a distancia. Esto es importante pues todo tuvo lugar rápidamente y dentro de un ambiente sanitario y socioeconómico también de excepción.

A la hora del análisis, este tuvo lugar a través de una matriz de organización de conceptos similares sociosemánticamente — campos sociosemánticos—en torno a cada pregunta y su narración — tras leer y releer los testimonios-, palabras y oraciones, así como, concepciones complejas de significados asociados en su contexto social, clasificados según el componente emocional y cognitivo, por una parte, y de otra, la función optimista, pesimista y neutra de la actitud, que fueron las seleccionadas para este estudio. En cuanto a la exposición de los resultados se confeccionaron unas tablas o cuadros que ilustran de forma resumida y a modo de campos socio semánticos las actitudes declaradas en el ejercicio realizado, lo cual está seguido de una explicación a modo de análisis e interpretación sobre las expresiones recabadas, y en algunos momentos cuando se considera oportuno también se trae a este texto fragmentos seleccionados de los mismos redactados para ejemplarizar los esquemas conceptuales presentados en la propia voz de los sujetos. Finalmente, reiterar el enfoque cualitativo de la investigación, no obstante, a la hora de esbozar los sentires y posicionamientos de los sujetos de estudio tiene lugar cierta comparación y un análisis tendencial de opinión que esboza cuantitativamente el panorama actitudinal. 


\section{Resultados}

\subsection{Allá y entonces}

Aquí se revisa la primera cuestión planteada: "Al oír por primera vez sobre el coronavirus en China: ¿Qué sentiste? YQQué pensaste?” (Tabla 1). Aquí el objeto actitudinal es la autovaloración cognitiva y emocional ante la noticia del virus y pandemia en el país asiático. Se obvió un interrogante sobre la acción o el aspecto conductual, ya que se consideró más oportuno ceñirse a lo sentido y pensado.

En primer lugar, decir que en este tema las emociones fueron pocas, mientras las exposiciones de lo que pensaron, abundantes y relativamente extensas, sobre todo comparativamente hablando. En cuanto a lo que sienten y el modelo actitudinal de la emoción, hay una importancia numérica de la valoración neutra hacia la situación, en el sentido que, no sentían nada pues no era algo importante, dijeron. En cuanto a la actitud positiva optimista o sana emocional se produjo interés, curiosidad y empatía hacia la población china. La negativa y pesimista, daba lugar a la incertidumbre y la preocupación en primer lugar, señalado esto por varias personas, también sorpresa y asombro que se han ubicado en este lugar pues es expresión sorpresa de algo inesperado, pero con tintes negativos, esto es, una valencia afectiva relacionada con lo negativo.

Respecto a los pensamientos y el modelo cognitivo sobre lo que piensan desde una valencia o valoración positiva y optimista, se habla de saber primero, y luego informar y prevenir, todo lo cual es un pensamiento, no obstante, ya indica el hacer y lo conductual, pero repetimos se centra en el pensamiento, y luego se dice que hay que tomar medidas sanitarias con objeto de controlar el virus y salir adelante. Ya en la línea negativa y pesimista sobre el pensar aparece la concepción de inverosímil y la comparación con las películas apocalípticas sobre epidemias y contagios, y para seguir en este discurso distópico se cree y evalúa que será una pandemia grave y larga, con muertes y a escala mundial. Luego aparecen una serie de ideas que tienen que ver con buscar una explicación al origen o causa, e incluso las consecuencias económicas. Finalmente, según la valoración neutra, hay una gran profusión de expresiones en el sentido de que es algo sin importancia, lejano y no llegará, se solucionará pronto, se tendrá la cura y no saldrá de China, y por lo tanto no llegará a México.

Lo anterior es sobre algo lejano temporal y sobre todo geográficamente, lo que sigue es ya más cercano en ambos sentidos. 
Tabla 1. Al oír por primera vez sobre el coronavirus en China: ¿Qué sentiste? y ¿Qué pensaste?

\begin{tabular}{|c|c|c|c|}
\hline \multicolumn{4}{|c|}{$\begin{array}{c}\text { Objeto actitudinal: } \\
\text { Al oír por primera vez sobre el coronavirus en China }\end{array}$} \\
\hline Valencia afectiva & Positiva-optimista & Negativa-pesimista & Neutra \\
\hline Modelo actitudinal & & & \\
\hline Sentiste-emoción & $\begin{array}{l}\text { Interés, curiosidad } \\
\text { Empatía (con los } \\
\text { chinos) }\end{array}$ & $\begin{array}{l}\text { Incertidumbre } \\
\text { Preocupación (por los } \\
\text { hospitales saturados) } \\
\text { Angustia } \\
\text { Sorpresa } \\
\text { Asombro } \\
\text { Confusión } \\
\text { Triste y necesario, } \\
\text { somos creadores } \\
\text { y destructores del } \\
\text { ecosistema }\end{array}$ & $\begin{array}{l}\text { Nada } \\
\text { No mucho } \\
\text { No importante } \\
\text { No presté atención } \\
\text { Indiferencia } \\
\text { Despreocupación } \\
\text { Me acordé de la } \\
\text { influenza AH1N1 } \\
\text { de } 2009 \\
\text { Era igual a la } \\
\text { influenza }\end{array}$ \\
\hline Pensaste-cognición & $\begin{array}{l}\text { Saber ¿qué es y } \\
\text { cómo se contagia? } \\
\text { Hay que informar } \\
\text { y prevenir } \\
\text { Hay que tomar } \\
\text { medidas sanitarias } \\
\text { para controlar } \\
\text { el virus y salir } \\
\text { adelante }\end{array}$ & $\begin{array}{l}\text { Inverosímil, eso solo } \\
\text { pasaba en las películas } \\
\text { apocalípticas } \\
\text { Sería una pandemia } \\
\text { con muchas muertes } \\
\text { La cura tardaría meses } \\
\text { Un problema grave a } \\
\text { escala mundial sino se } \\
\text { controlaba } \\
\text { Conspiración del } \\
\text { gobierno chino } \\
\text { Enfermedad creada por } \\
\text { el hombre } \\
\text { Crac económico como } \\
1929 \\
\text { Error comer animales } \\
\text { Represión gobierno } \\
\text { chino }\end{array}$ & $\begin{array}{l}\text { No le di importancia } \\
\text { Era un problema } \\
\text { lejano y no llegaría } \\
\text { Terminaría pronto } \\
\text { Se controlaría pronto } \\
\text { Se solucionaría } \\
\text { rápido } \\
\text { Brote aislado sin } \\
\text { importancia } \\
\text { Un problema en } \\
\text { China, pero no se } \\
\text { extendería } \\
\text { Se encontraría cura, } \\
\text { no llegaría a México } \\
\text { Lo vi para otros } \\
\text { países, pero muy } \\
\text { lejano }\end{array}$ \\
\hline
\end{tabular}

*Esta tabla muestra la emoción y cognición de las actitudes optimistas, pesimistas y neutras tras oír por primera vez sobre el coronavirus en China. 


\subsection{Aquí y ahora}

La siguiente interrogante gira sobre la llegada al país de la COVID-19, y los sentimientos y pensamientos al respecto.

Tabla 2. Cuando se informó que el coronavirus llegó a México: ¿Qué sentiste? ¿Qué pensaste?

\begin{tabular}{|c|c|c|c|}
\hline \multicolumn{4}{|c|}{ Objeto actitudinal: Cuando se informó que el coronavirus llegó a México } \\
\hline Valencia afectiva & Positiva-optimista & Negativa-pesimista & Neutra \\
\hline Modelo actitudinal & & & \\
\hline Sentiste-emoción & & $\begin{array}{l}\text { Sorprendida } \\
\text { Duda } \\
\text { Confusión } \\
\text { Asustado } \\
\text { Un poco de zozobra } \\
\text { Miedo, temor, terror, } \\
\text { pánico } \\
\text { Angustia } \\
\text { Estrés } \\
\text { Incertidumbre } \\
\text { Preocupación }\end{array}$ & $\begin{array}{l}\text { Nada } \\
\text { Indiferencia }\end{array}$ \\
\hline Pensaste-cognición & $\begin{array}{l}\text { Pensé, un mes y } \\
\text { termina pronto } \\
\text { Pronto acabaría } \\
\text { Pasará rápido, } \\
\text { no es nada } \\
\text { importante } \\
\text { Pensé que todo } \\
\text { estaría bajo } \\
\text { control y la gente } \\
\text { haría caso de las } \\
\text { indicaciones } \\
\text { Creí que en otros } \\
\text { países sí, pero } \\
\text { en México no } \\
\text { afectaría tanto }\end{array}$ & $\begin{array}{l}\text { Lo vi como algo irreal, } \\
\text { no podía estar pasando, } \\
\text { como el pasaje de una } \\
\text { película, un sueńo, y } \\
\text { despertaría } \\
\text { No imaginé algo como } \\
\text { lo actual } \\
\text { Situación grave } \\
\text { No pensé que fuera tan } \\
\text { rápido } \\
\text { No creí que llegara la } \\
\text { solución pronto } \\
\text { Problema de salud y } \\
\text { económico } \\
\text { Qué pasará con la gente } \\
\text { sin recursos }\end{array}$ & $\begin{array}{l}\text { ¿Me pregunté qué } \\
\text { pasará? } \\
\text { ¿Qué hará el país? } \\
\text { ¿Con qué medios } \\
\text { y qué medidas } \\
\text { cuenta el país? } \\
\text { ¿Cuánto duraría? } \\
\text { Y ¿Qué medidas } \\
\text { tomar? }\end{array}$ \\
\hline
\end{tabular}




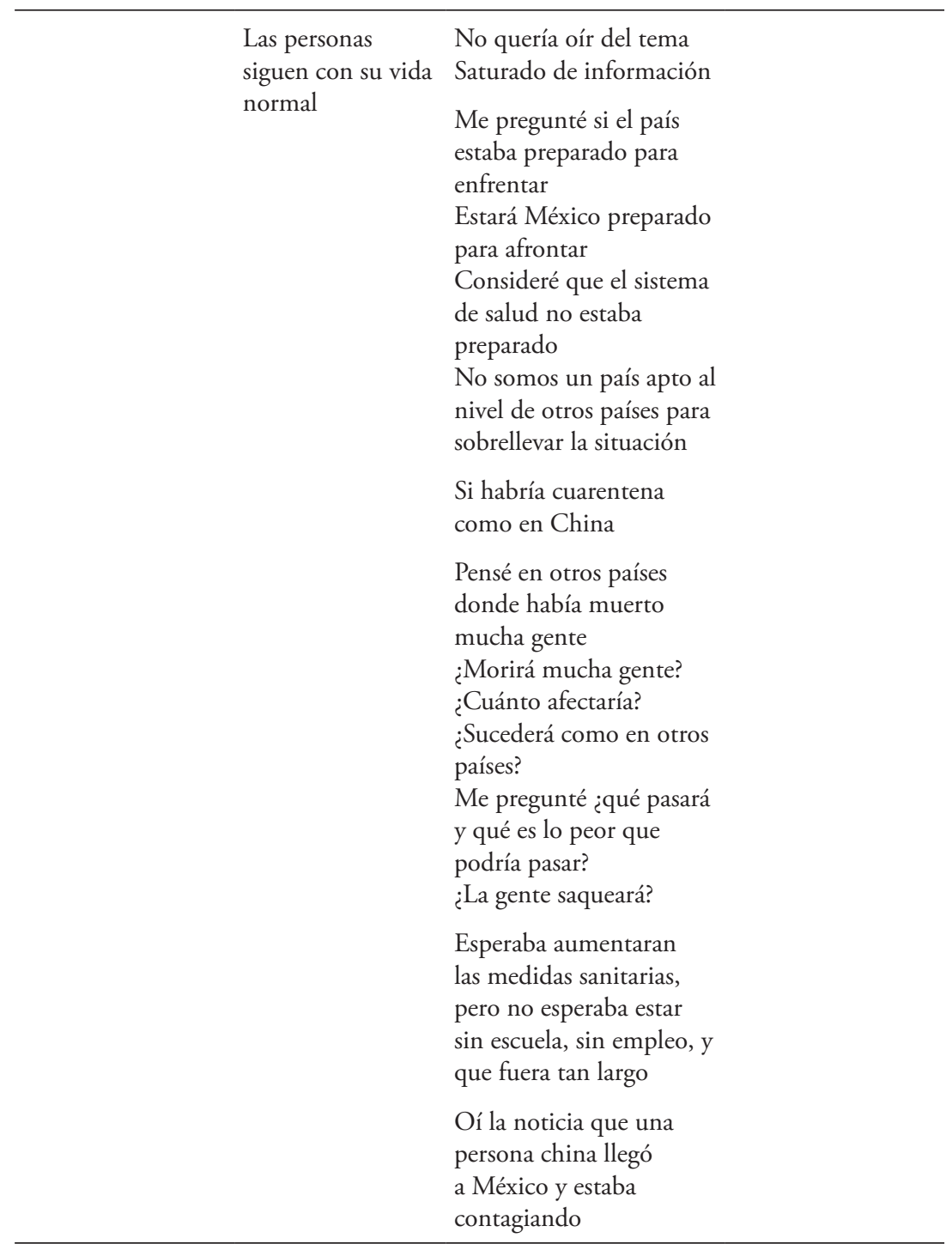

*Esta tabla presenta el componente emocional y cognitivo de la actitud, según su función optimista, pesimista y neutra.

Aquí como en el punto anterior, hubo expresión de sentimiento más o menos breve y directa, sin embargo, la parte del pensamiento fue más larga y explicativa incluso reflexiva, esto es, lo que dicen que pensaron al llegar el coronavirus a México. Como se observa en la Tabla 2, lo emocional como 
parte del concepto de actitud valorativa de la situación apunta al tipo de valencia neutral y hubo quien relató no haber sentido nada o indiferencia. Sin embargo, la valoración de la mayoría fue negativa y pesimista, desde la sorpresa, duda y confusión, hasta el miedo, la angustia, la incertidumbre y la preocupación, que fueron las más señaladas y se repitieron una y otra vez. No se encontraron expresiones positivas y optimistas.

Respecto a la cognición de la valoración de lo que acontecía, fueron numerosos y amplios los testimonios recabados. Para empezar, se esbozaron algunas preguntas que en principio podría pensarse estaban en tono neutro, sobre qué pasará, qué medidas tomar o cuánto durará. Sobre la actitud positiva se expusieron también pensamientos en el sentido que todo iba a durar poco y pasar pronto, que todo iba estar bajo control y se podría seguir con la vida normal. Eso sí, la mayoría de los relatos sobre los pensamientos fueron en el sentido negativo-pesimista, en diferentes líneas semánticas, desde lo irreal e incluso inimaginable que parecía una película o un sueño del que se esperaba despertar -como en la anterior pregunta-, pasando por lo grave, lo rápido, la saturación de información, las muertes en varios países y lo que pasará en México, incluso lo peor que podría pasar. Los problemas de salud y también los económicos, y la gente sin recursos. Algo en lo que se centró el pensamiento también es si el país y el sistema sanitario estaban preparados para enfrentar, afrontar y sobrellevar la crisis, lo cual apareció de forma reiterada en varios testimonios.

Ahora se aborda la instrucción de la jornada de sana distancia, el quedarse en casa, o sea, el confinamiento que en esos momentos se estaba viviendo.

En este caso del confinamiento (Tabla 3), las emociones fueron más numerosas, señal de cómo afecta este distanciamiento social emocionalmente, aunque no tanto como los pensamientos que una vez más fueron más extensos. En este segundo caso más que la afectación se puede observar esta de forma indirecta a través de lo que dicen que piensan. Para el primer punto, las emociones, no se presentaron las que tienen enfoque neutro, y si bien abundaron las negativas, hay que decir que también aparecen las positivas. Esto por supuesto hay que explicarlo, ya que las positivas u optimistas tienen que ver con hacer las cosas consideradas correctas para el cuidado de la salud según la situación, y que es juzgado como lo mejor, entre ellas aparecieron la seguridad y tranquilidad, así como el alivio y la satisfacción. En el caso de las que muestran una actitud negativa y pesimista, las más numerosos, y fueron en primer lugar la desesperación, juntamente con la ansiedad y el estrés, seguidas de la frustración y preocupación, además de todas las demás que aparecen en la tabla correspondiente. 
Tabla 3. Sobre el confinamiento que está teniendo lugar: ¿Qué sientes? ¿Qué piensas?

\begin{tabular}{|c|c|c|c|}
\hline \multicolumn{4}{|c|}{ Objeto actitudinal: Sobre el confinamiento que está teniendo lugar } \\
\hline Valencia afectiva & Positiva-optimista & Negativa-pesimista & Neutra \\
\hline Modelo actitudinal & & & \\
\hline Sientes-emoción & $\begin{array}{l}\text { Alivio } \\
\text { Seguridad } \\
\text { Tranquilidad } \\
\text { Confianza } \\
\text { Satisfacción } \\
\text { Comodidad } \\
\text { Momentos } \\
\text { agradables } \\
\text { (hacer lo que } \\
\text { dicen, medidas } \\
\text { necesarias, mejor } \\
\text { solución, estoy } \\
\text { con mi familia, no } \\
\text { me molesta estar } \\
\text { en casa) }\end{array}$ & $\begin{array}{l}\text { Desesperación } \\
\text { Frustración } \\
\text { Impotencia } \\
\text { Estrés } \\
\text { Ansiedad } \\
\text { Incertidumbre } \\
\text { Vulnerable } \\
\text { Mal } \\
\text { Ira } \\
\text { Tristeza } \\
\text { Preocupación } \\
\text { Inquietud } \\
\text { Zozobra } \\
\text { Confundida } \\
\text { (no me gusta, no } \\
\text { estoy acostumbrada, el } \\
\text { encierro, no ver amigos, } \\
\text { no ver personas que } \\
\text { quiero, no visitar lugares, } \\
\text { por mí, por mi familia }\end{array}$ & \\
\hline Piensas-cognición & $\begin{array}{l}\text { Buena estrategia } \\
\text { cumplir todo para } \\
\text { salir pronto } \\
\text { Esperar el tiempo } \\
\text { necesario } \\
\text { Lo mejor que se } \\
\text { puede hacer para } \\
\text { evitar contagios } \\
\text { Respetar y seguir } \\
\text { el protocolo }\end{array}$ & $\begin{array}{l}\text { Afecta a la población } \\
\text { por inconsciente, por } \\
\text { ignorancia, por no tomar } \\
\text { precauciones } \\
\text { La gente no lo toma en } \\
\text { serio } \\
\text { Las personas siguen } \\
\text { haciendo caso omiso y } \\
\text { esto va a seguir así }\end{array}$ & $\begin{array}{l}\text { ¿Cuándo acabará el } \\
\text { encierro? } \\
\text { Tal vez la vida no } \\
\text { vuelva a ser como } \\
\text { antes } \\
\text { Nuestra vida } \\
\text { cambiará no será la } \\
\text { misma de antes } \\
\text { Ya nada será igual } \\
\text { Intriga cómo } \\
\text { estarán las cosas al } \\
\text { volver a la nueva } \\
\text { normalidad }\end{array}$ \\
\hline
\end{tabular}




\begin{tabular}{lll}
\hline $\begin{array}{l}\text { Hacer un esfuerzo } \\
\text { y no entrar en } \\
\text { estados mentales } \\
\text { negativos }\end{array}$ & $\begin{array}{l}\text { No todo el mundo tiene } \\
\text { el privilegio de estar sin } \\
\text { hacer nada }\end{array}$ & $\begin{array}{l}\text { Una situación que } \\
\text { nos marcará de por } \\
\text { vida }\end{array}$ \\
$\begin{array}{l}\text { las fechas para no } \\
\text { predisponerme a } \\
\text { ilusionarme }\end{array}$ & $\begin{array}{l}\text { Como medida preventiva } \\
\text { semardaron }\end{array}$ & esto acabe \\
una oportunidad & Yo quiero que se acabe, \\
para conocernos & los mexicanos no \\
mental y & nacimos para quedarnos \\
espiritualmente & quietos en nuestros \\
hyudar & hogares. \\
Necesitamos & Es complicado salir de \\
apoyarnos & compras \\
\hline
\end{tabular}

*Esta tabla muestra las emociones y cogniciones actitudinales según su función optimista, pesimista $y$ neutra.

Con relación a las actitudes que valoran la situación del confinamiento, hay que decir que hubo variedad de opinión, desde posturas neutras en el sentido de preguntas tipo monólogo o reflexiones sobre los cambios que esto traerá sin precisar en qué sentido, hasta posicionamientos de pensamientos positivos, en el sentido de estar de acuerdo con las medidas oficiales, siendo juzgadas como correctas y lo mejor que dadas las circunstancias se puede hacer. Así aparecen afirmaciones de que es buena la estrategia y de que hay que respetar el protocolo. Luego hay otros dos campos semánticos, uno que tiene que ver con ayudar y apoyarse, y otro que alumbra la introspección propia, desde evitar estados mentales no saludables hasta el aprovechar la oportunidad para auto conocerse y desarrollarse como humanos. Finalmente, la actitud valorativa negativa desde el pensamiento apunta en buena parte a juzgar a aquellos que no respetan las medidas, hasta incluso acusarlos del contagio y la permanencia de la enfermedad y las medidas mismas de forma directa o indirectamente. Si bien hay alguna voz comprensiva que se alza a favor de quienes precisan trabajar para vivir. Así también, aparece el deseo que todo finalice y volver a salir a la vida cotidiana supuestamente normal.

Con este panorama cognitivo, de creencias, evaluaciones y valores, así como de sentimientos y emociones o estados de ánimo es que llegamos al tema educativo. 


\subsection{La educación a distancia}

La educación a distancia o remota como se denominó oficialmente en la UAM (Tabla 4), es la última pregunta que revisamos en estas páginas y esperamos mostrar el panorama de sentimientos y pensamientos al respecto, ello con el objetivo de conocer cómo se ha experimentado esta transición a lo digital, o mejor dicho transformación brusca e inesperada.

Tabla 4. Sobre las clases a distancia: ¿Qué sientes? ¿Qué piensas?

Objeto actitudinal: Sobre las clases a distancia

\begin{tabular}{llll}
\hline Valencia afectiva & Positiva-optimista & Negativa-pesimista & Neutra \\
\hline & & \\
\hline Modelo actitudinal \\
\hline
\end{tabular}

\begin{tabular}{lll}
\hline Sientes-emoción & $\begin{array}{l}\text { Satisfacción por } \\
\text { continuar }\end{array}$ & Estresante, estrés \\
Agradecimiento & Desesperado \\
Felicidad por no & Desanimada \\
perder el trimestre & Tristeza \\
Entusiasmo de & Aburrimiento \\
poder seguir & Extrañeza \\
estudiando & Raro \\
Cómoda, aunque & Incomodidad \\
extraño asistir & & \\
& (por las plataformas, \\
& la distancia con \\
& los profesores, \\
& cuesta organizarse y \\
& concentrarse, poco \\
& satisfactorias, no saber \\
& utilizar los medios) (no \\
& son comparables con las \\
& presenciales) \\
& Extraño \\
& (las clases presenciales, \\
a los compañeros y a los & profesores) \\
& Quiero volver \\
&
\end{tabular}




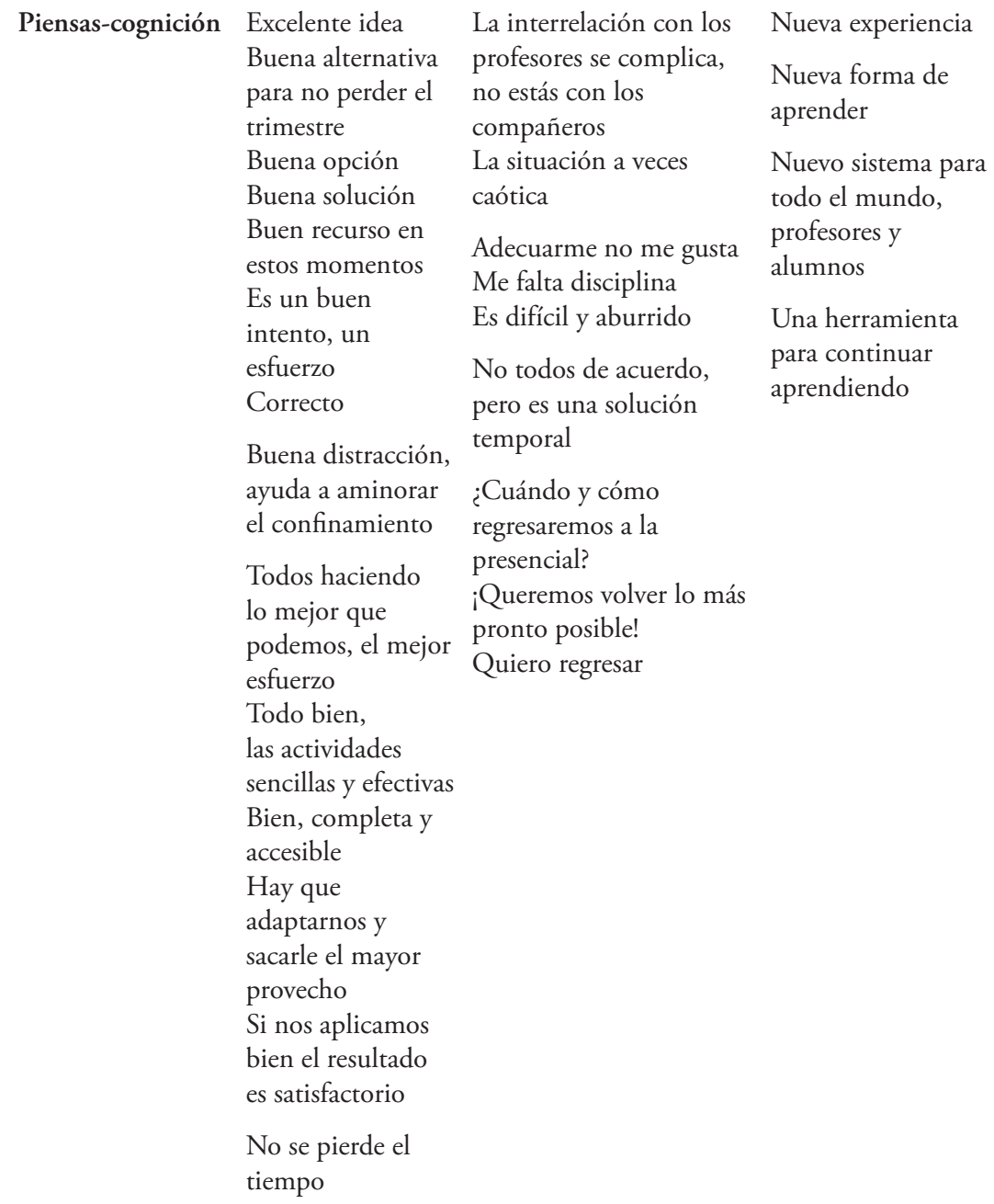

*Esta tabla presenta la parte emocional y cognitiva de la actitud según sus funciones optimistas, pesimistas y neutras.

$\mathrm{Si}$ bien esto es un acercamiento exploratorio, cualitativo y general (Valles, 1997) con las limitaciones de investigación del momento (Lupton, 2020) es importante saber y tener en cuenta cómo el alumnado ha vivido - o sobrevivido si así se desea ver- al trimestre de docencia remoto que cursó entre mayo y julio del año 2020 en la UAM/X, debido a las circunstancias sanitarias y a las jornadas de sana distancia impuestas en el país, eso sí, contextualizar 
el redactado que se elaboró a la mitad del mismo, o sea en pleno periodo lectivo, con lo que tiene de vivencia y riqueza pues son las expresiones que reflejan lo pensado y sentido. Obtener una suerte de valoración-evaluación, reiteramos, general, pero significativa y en sus propias palabras, a través de un relato descriptivo que respondía una pregunta concreta y de forma breve esboce desde la cognición y la emoción, la valoración experiencial que aquí se clasifica a modo de campos semánticos y según la tipología de las actitudes, como positiva, negativa y neutra.

Curiosamente, y en comparación y a diferencia de las tres preguntas y temáticas anteriores, en el caso de la educación a distancia hubo más sentimientos declarados, y si bien nuevamente las explicaciones sobre pensamientos siguen siendo más abundantes y extensas, no hay tanta diferencia como se observó en los puntos anteriores, lo cual es digno de señalarse, pues de alguna manera equivale a la importancia emocional de la vivencia escolar, central para muchos/as en sus vidas.

En primer lugar, las actitudes emocionales valorativas neutras no existieron, y si bien las negativas superaron cuantitativamente a las positivas, estas hay que mencionarlas, y su sentido es con relación al entusiasmo de no perder el trimestre, incluso el agradecimiento que expresan sobre el asunto.

"Entusiasmo, porque asi podemos seguir estudiando"

"Felicidad, no se perderá el trimestre y no se me hace pesado estudiar asi"

"Me siento bastante cómoda, pero aún extraño asistir a la universidad presencialmente"

En cuanto a las negativas sobresale la desesperación y el estrés por las dificultades de realizar el estudio de forma satisfactoria y cómoda, debido a múltiples factores, desde la dificultad tecnológica hasta el propio estado de ánimo, también pesa la distancia física con el profesorado y entre las y los compañeros de grupo, ello supuestamente por razones lógicas de aprendizaje y también de afectividad.

"Extrañeza al ser la primera vez que tomo clases como estas"

"Me siento un poco desesperado, pues no es igual que las clases presenciales"

"Me siento un poco desanimada, ya que extraño las clases presenciales"

"Extraño no llegar a los salones a escuchar los bulliciosos compañeros"

"Siento que es un poco complicado y a veces puede frustrarte porque el profesor no entiende tu duda"

Ya en los relatos sobre lo cognitivo y el pensamiento, aparecen en ocasiones

la descripción valorativa de carácter neutro, en el sentido que es algo nuevo, 
nuevo sistema, nueva herramienta, nuevo aprendizaje, nueva experiencia y para todo mundo, incluyendo estudiantes y equipo docente.

"Una nueva forma de aprender"

"Pienso que es un buen recurso en estos momentos"

"Una herramienta para continuar con el aprendizaje a pesar de la crisis que estamos pasando actualmente"

Aquí los pensamientos valorativos de la iniciativa de la educación remota sobresalen en el aspecto positivo con mucha diferencia del negativo. En cuanto a este último, el no convivir con el grupo y las dificultades comunicativas con el profesor son una causa esbozada de esta actitud.

"Que tengo que adecuarme a las medidas necesarias para seguir con mis estudios y que no me gusta mucho este estilo de estudio"

"Siento que es una nueva forma de tomar clase en la que todos no están de acuerdo, yo la considero una solución temporal"

"Me estreso y me cuesta trabajo organizarme y concentrarme. Me falta disciplina y rutina que implicaba ir a clases, asi como la interacción con mis profesores y compañeros"

Lo cual no implicaba no reconocer las propias limitaciones emocionales y mentales, así como, la insistencia en la necesidad de adaptación a la nueva situación y a la implementación de las nuevas modalidades y estrategias de enseñanza aprendizaje, como se ha visto. Además, una y otra vez, con diferentes expresiones, desde preguntas hasta exclamaciones o incluso súplicas, se decía que se quería volver a las clases presenciales, como mostraremos en el último punto.

Respecto a las segundas, o sea las positivas, el cuórum se centraba en que era lo que se podía hacer y sobre todo así no se perdía el trimestre, la palabra buena apareció una y otra vez, desde buena idea a buena alternativa, recurso y solución del problema, incluso distracción ante el confinamiento añadió una joven.

"Me parece una excelente idea que no perdiéramos o nos atrasásemos en las clases, $y$ de esta forma estemos cursando"

"Es una buena idea retomar las clases en línea, asi no se pierde tanto tiempo y realizamos cosas de provecho"

"Pienso que es una buena alternativa, aunque por momentos llega a ser algo estresante para mi, porque el hecho de utilizar unicamente plataformas para realizar actividades se me dificulta a veces y me estresa". 
Si bien hay cierta generalidad de que, dentro de todas las limitaciones reales, los esfuerzos desplegados, el balance puede ser positivo.

"Que, a pesar de todo, se ha llevado a cabo bien las actividades de manera sencilla, pero efectiva"

"En mi caso, a pesar de la distancia, se han realizado las actividades de una manera completa y accesible"

"Una buena idea y puede que gracias a esto la UAM integre las clases en línea"

Y también se reconoció al unísono el esfuerzo que todo mundo hacía, y la necesidad de aceptar la situación y la experiencia y aplicarse. Así las cosas, esta mirada satisfactoria y que considera que todo está lo mejor posible parece mayoritaria.

"Que todos estamos haciendo lo mejor que podemos, y que si nos sentimos frustrados o estresados es normal y está bien. El esfuerzo que estamos haciendo es más que suficiente"

"Que este es un nuevo sistema, tanto para los profesores como los alumnos, debemos ser muy accesibles, para que todo se lleve de la mejor manera" "Que son estresantes y poco satisfactorias, pero comprendo el intento y el esfuerzo por parte de la universidad por brindarnos la oportunidad de no perder el trimestre y lo agradezco enormemente"

"Son alternativas, que bien aplicadas darian un resultado más satisfactorio, pero también me pongo del lado de la universidad que decidió hacer el plan de estudios en menos de un mes"

Pues según esto, con sus problemáticas concretas, de distanciamiento social humano entre los actores educativos, o las complicaciones tecnológicas, incluso los mermados estados anímicos de ellos mismos, aparentemente parece juzgar casi todo de forma positiva y optimista, con una actitud que es posible calificar como además de positiva y optimista, como colaboradora e integradora, asertiva, flexible, proactiva y empática, de forma amplia (Bohner y Dikel, 2010; Ajzen, 2005).

"Que es una nueva situación y que a pesar de que a veces resulta caótica, estamos todos en esta curva de aprendizaje y es completamente normal que nos pueda parecer demandante y que nos sobrepase. El objetivo es adaptarnos y sacarle el mayor provecho posible"

"Hay que tener comprensión al entender esta situación y que no es fácil realizar clases en línea, ya que nuestro programa normalmente es dinámico y presencial $y$ de trabajo colaborativo" 


\section{Discusión}

En resumen, según lo visto se señala que al inicio hubo sorpresa, a veces con curiosidad otras teñida ya de incertidumbre, así como, bastantes expresiones neutrales, por aquello de la distancia geográfica, cuando se dio la noticia del coronavirus en China en el mes de enero de 2020. Ya al llegar a México se pasó a una valoración actitudinal más negativa y pesimista tanto de pensamiento como de sentimiento, pues se navegó de la sorpresa al miedo, y a la evaluación de que algo grave sucedía, con la duda reiterada de si la sanidad del país podría afrontar satisfactoriamente el problema de salud que iniciaba. Ya con la consigna del quédate en casa se observa una actitud con emociones positivas y negativas, si bien con más intensidad y en mayor número las segundas; mientras también el pensamiento se muestra pesimista con alguna consideración de carácter optimista. De la tranquilidad de poder seguir las medidas sanitarias a la desesperación e incertidumbre de sentirse encerrados. De la consideración que es lo mejor que se puede hacer, al juicio y acusación de aquellas personas que incumplen y salen de casa y no toman precaución alguna.

Finalmente, en cuanto a la educación a distancia de la UAM/X (UAM, 2020), aquí recogido como objeto actitudinal y según los relatos de por supuesto la muestra consultada, aparece satisfacción y felicidad de seguir estudiando y no perder el trimestre, también estrés y frustración por el distanciamiento físico educativo, de profesores y compañeros, a lo que hay que ańadir desánimo e incomodidad por el uso masivo e intensivo de las nuevas tecnologías de la comunicación, esto en la actitud valorativa emocional de la situación. Según el pensamiento de las personas consultadas se aprueba la propuesta e incluso la experiencia que se está llevando a cabo, por la necesidad de las circunstancias y el interés de proseguir el proceso educativo y de no perder el trimestre, nuevamente, además de la reiterada valoración del esfuerzo colectivo de la institución y de todos los actores educativos involucrados. No obstante, los problemas y dificultades en la enseñanza aprendizaje por cuestiones técnicas, sociales y también de carácter personal. Eso sí, la insistencia expresada cuasi unánimemente y el deseo expreso de querer regresar a la escuela y a las clases presenciales, cuanto antes, es un clamor importante.

"Me pregunto cuándo y de qué manera será el regreso a clase. También me llama la atención cómo se tornará la situación en los próximos meses" "Quiero volver lo más pronto posible a nuestras instalaciones, convivir y poder llevar tu vida escolar, como siempre lo habiamos hecho" "Ya quiero regresar a la escuela y ver a mis amigos" 
Añadir que de las funciones de las actitudes (Briñol et al., 2007; Ubillos et al., 2014), también se observó cómo en este grupo estudiantil se procesa la información del entorno y se ofrece un orden y se le da un significado, todo adaptándose a las circunstancias sociales y sanitarias, y cómo se expresa esto directamente en sus palabras, así como, se desarrolla la actitud defensiva al indicar no dejarse arrastrar por ciertos estados mentales, o la utilitarista cuando se considera seguro el quedarse en casa y se intenta alejar la ansiedad, aunque sea a través del estudio.

Y sobre las otras tipologías de las actitudes, además de las ya presentadas que constituyen el núcleo de esta investigación y el estudio de caso, mencionar que sí hay desde posiciones reactivas a las proactivas, si bien estas últimas destacan en el punto de la educación remota, así también se observa el interés del beneficio colectivo tanto en la preocupación por la gente sin recursos, como y sobre todo en el reconocimiento del esfuerzo que la comunidad universitaria realiza, además de una postura colaborativa en general con las normas sanitarias del país y los cambios educativos de la universidad, la asertividad y la flexibilidad parecen sobresalir en general. Así que dentro del panorama general que puede ser calificado como complicado y complejo, y con actitudes valorativas del mismo que se decantan hacia observar las dificultades y adversidades, se abren paso también la actitudes optimistas y positivas que estimulan hacia la acción, a seguir adelante con la vida adaptada a las circunstancias y a proseguir con el proceso educativo adecuado también a las nuevas modalidades que con sus problemáticas se afrontaron y sobrellevaron positivamente. Aquí conviene pensar en el peso que las emociones denominadas positivas, y que aquí se han centrado en actitudes, y los estados anímicos ante la educación y la vida que cobran un valor muy significativo (Fredrickson, 2004; Seligman, 2014).

\section{Conclusiones}

Si bien, y como ya se expuso en un inicio, este es un estudio de caso, inicial y aproximativo al tema, de carácter cualitativo y exploratorio. Quizás es un principio de acercamiento para tomar el pulso de cómo estamos como país, sociedad y comunidad educativa, cómo pese a la perdurabilidad de las actitudes - quiero regresar a clases presenciales - se levanta la actitud de adaptación —es lo mejor que se puede hacer y todo mundo hace su mejor esfuerzo-, sin negar la ambivalencia, felicidad -por proseguir el proceso enseńanza aprendizaje y no perder el trimestre- frente al estrés y desesperación -por las dificultades técnicas y el distanciamiento físico escolar. 
Todo ello en el marco existencial de quien afirma que nada volverá a ser como antes, o que esto le ha servido para reflexionar sobre su propia vida, siempre con el deseo y motivación como marco de fondo de querer seguir estudiando y aprendiendo, parte de lo que hoy se ha dado en llamar el conocimiento a lo largo de la vida (ONU, 2014), y que al parecer va a seguir operando e incrementando su importancia hacia el porvenir, con el añadido de la preponderancia de la educación a distancia.

\section{REFERENCIAS BIBLIOGRÁFICAS}

Ajzen, Ic. (2005). Attitudes, Personality, and Behavior. Open University Press, McGraw-Hill Education (UK). Recuperado de https://psicoexperimental. files.wordpress.com/2011/03/ajzeni-2005-attitudes-personality-andbehaviour-2nd-ed-open-university-press.pdf

Allport, G. (1935). Attitudes in Murchison (Ed.), Handbook of social psychology. Worcester: Clark University Press.

Bohner, G., Dikel, N. (2010). Attitudes and attitude change. Annual Review of Psychology, 62, 391-417. https://doi.org/10.1146/annurev. psych.121208.131609

Brińol, P., Falces, C., Becerra, A. (2007). Actitudes en J. F. Morales, C. Huici; M. Moya, E. Gaviria (Eds.), Psicología Social. (pp. 457-490) Madrid: McGraw-Hill.

Cohen, N. y Seid, G. (2019). Producción y análisis de datos cualitativos. En N. Cohen y G. Gómez Rojas (Coords.), Metodología de la investigación ¿Para qué? (pp. 203-227). Buenos Aires: Teseo/CLACSO. https://doi. org/10.2307/j.ctvxcrxxz.10

Corrales, C. (1991). El estudio de los campos semánticos. Revista de Filología, 10, 79-93.

Díaz, C. (2000). El análisis sociosemántico en la psicología social: una propuesta teórica y una técnica para su aplicación. Psicothema, 12, 451-457.

Dussel, E. (2020). El COVID-19 jaqueó la modernidad. Recuperado de https:// www.mugsnoticias.com.mx/noticias-del-dia/el-covid-19-jaqueo-lamodernidad-enrique-dussel/

Fredrickson, B. (2004). El poder de los buenos sentimientos. Mente y cerebro, 8, 74-78.

Han, B-C. (2014). La sociedad del cansancio. Barcelona: Herder.

Han, B-C. (2020). La emergencia viral y el mundo de mañana. En G. Agamben et al. (Coords.), Sopa de Wuhan. (pp. 97-112). S.1.: ASPO. 
Kuhn, T. (1986). La estructura de las revoluciones cientificas. México: FCE.

Lasalle, J. M. (2019). Ciberleviatán. Barcelona: Arpa.

Lupton, D. (2020). Doing Fieldwork in a Pandemic. Recuperado de https:// nwssdtpacuk.files.wordpress.com/2020/04/doing-fieldwork-in-a-pandemic2-google-docs.pdf

Organización Mundial de la Salud (OMS) (2020). COVID-19: cronología de la actuación de la OMS. Recuperado de https://www.who.int/es/news-room/ detail/27-04-2020-who-timeline---covid-19

Organización de las Naciones Unidas (ONU) (2020). Construir hoy el futuro de la Educación. Recuperado de https://www.un.org/es/coronavirus/articles/ future-education-here

Rodríguez, J.M. (2004). Estructura semántica y análisis ideológico. Filología y Lingüística, 30 (2), 155-169.

Rogers, C. (2007). El proceso de convertirse en persona. Barcelona: Paidós.

Seligman, M. (2014). La auténtica felicidad. Barcelona: Zeta.

Organización de las Naciones Unidas para la Educación, la Ciencia y la Cultura Unesco (2014). Estrategia a plazo medio. Recuperado de https://unesdoc. unesco.org/ark:/48223/pf0000231112

Universidad Autónoma Metropolitana (UAM) (2020). Informe ejecutivo. Proyecto Emergente de Educación Remota. Recuperado de www.uam.mx

Ubillos, S., Mayordomo, S. y Páez, D. (2014). Actitudes: definición y medición. Componentes de la actitud. Modelo de la Acción Razonada y Acción Planificada. En D. Páez, I. Fernández, S. Ubillos y E. Zubieta (coords.), Psicología Social, Cultura y Educación (pp. 301-339). Madrid: Pearson Educación.

Valles, M. (1997). Técnicas cualitativas de investigación social. Madrid: Síntesis.

Zibechi, R. (2020). A las puertas de un nuevo orden mundial. En G. Agamben et al. (Coords.), Sopa de Wuhan. (pp. 113-118). S.1.: ASPO

Zizek, S. (2020). El coronavirus es un golpe al capitalismo a lo Kill Bill en Agamben, G. et al. (Coords.), Sopa de Wuhan (pp. 21-28). S.l.: ASPO. 